\title{
LA PERCEPCIÓN DE LO BELLO EN EL DE VERA RELIGIONE DE SAN AGUSTÍN
}

\section{Dr. Hugo Emilio Costarelli Brandi*}

Es indudable que para San Agustín la Belleza es un Absoluto que, además de fundar todo lo real, impregna la creación con su huella invitando al hombre a recorrerla y llegar finalmente a su descubrimiento. Pero tal descubrimiento no es inmediato sino que implica el recorrido de ciertos niveles humanos de percepción. El presente trabajo se ocupará, entonces, de esos momentos perceptivos de lo bello en el hombre, pero analizados desde la particular óptica del De Vera Religione.

Palabras clave: San Agustín, Belleza, percepción, experiencia.

\section{THE PERCEPTION OF THE BEAUTIFUL IN ST. AUGUSTINE'S $D E$ VERA RELIGIONE}

\begin{abstract}
It is unquestionable that, for St. Augustine, Beauty it is an Absolute that, besides being at the foundation of all reality, impregnates Creation with its mark, inviting Man to explore it and arrive finally at its discovery. But such a discovery is not immediate; rather, it supposes the transition through certain human levels of perception. The present paper will concern itself, therefore, with these perceptive moments of the beautiful in Man, yet analyzed from the particular point of view of the De Vera Religione.
\end{abstract}

Keywords: Saint Augustine, Beauty, perception, experience.

\footnotetext{
• Universidad Nacional de Cuyo, Mendoza, Argentina. Correo electrónico: hugo_brandi@yahoo.com.ar
} 


\section{Introducción}

Todo el QUe DE UN MODO u OTRO HA RECORRIDo LAS PÁGINAS de las Confesiones de San Agustín ha notado con inmenso gozo ese momento culminante donde el Hiponense llega a la belleza verdadera: «Tarde te amé, hermosura tan antigua y tan nueva, tarde te amé!»!. La extraordinaria fuerza de esța breve frase, fruto maduro de un importante recorrido donde Dios se ha terminado revelando en la intimidad del ser humano, pone al lector atento en un singular estado: el asombro de ver cómo la interioridad de otro hombre ha llegado a la percepción de una Belleza fundante.

Sin embargo, se debe advertir que el lector permanece en este punto de distinto modo que Agustín, pues el Hiponense es quien ha realizado el ascenso, y quien lee, sólo percibe la maravilla del mismo y la intensidad de lo vivido, sin por ello revivir de igual manera lo relatado por el autor. ¿Significa esto que quien se admira con las palabras del Obispo de Hipona desconoce por completo de lo que se está hablando? Si así fuera, entoncess ningún asombro podría experimentarse ante lo dicho, de manera que, aunque poco, algo se está comprendiendo.

Esta mezcla de comprensión y no comprensión ocurre porque el camino trazado por el Obispo de Hipona es posible a todo hombre, pues pertenece a la naturaleza humana la tensión constante al encuentro con una Belleza superior, con una que es su plenitud y felicidad. Sin embargo, es manifiesto que si quien lee no ha alcanzado lo que Agustín describe, si no llega a descubrir existencial o experimentalmente esa Belleza, es porque aún la vocación contenida potencialmente en él no se ha desplegado.

En efecto, el cumplimiento de la vocación humana debe ser conquistado de a poco; o de otro modo, la reunión con lo Bello ha de alcanzarse progresivamente. En este sentido el $D e$ Vera Religione plantea en sus páginas un singular camino humano de ascenso a la Belleza que, partiendo deșde la sensibilidad, alcanza la percepción intelectual del Pulchrum como así también del fundamento de toda captación de lo bello.

\footnotetext{
Agustin de Hipona, San, Confesiones, X, 27, 38, trad. de Vega, Ángel Custodio, BAC, Madrid, 1991.
} 
El presente trabajo se situará, entonces, en este último escrito con la intención de analizar la percepción de lo bello, tal como la plantea el texto, notando los distintos niveles en que ella puede darse, como así también su fundamento ${ }^{2}$.

\section{La percepción de lo bello sensible: su lugar y sentido}

Es conocido el profundo carácter antimaniqueo que presenta el De Vera Religione. Esto explica la insistencia de Agustín en que el primer ámbito de captación de lo bello, allí donde se ofrece la posibilidad del ascenso a bellezas más profundas sea, justamente, el de las hermosuras materiales y defienda de igual manera ese estrato de lo bello, para que así éste alcance su justo y adecuado lugar.

Ya Platón había examinado este punto, al subrayar que en el ascenso a la Belleza Absoluta no se puede eludir este primer escalón, so pena de quedar varado en las sombras de la caverna ${ }^{3}$. Sin embargo, el mismo Platón al realizar ese ascenso había partido desde los cuerpos humanos, pues su propia metafísica le hacía ver con desconfianza el resto de las cosas materiales. El Hiponense, por el contrario, conocedor del hecho de la Creación, propondrá un ascenso a partir de la misma belleza natural, la de las criaturas que rodean al hombre, pues está seguro de que si ellas han sido puestas en el ser por Dios, deben ser una huella de su Hacedor.

Así, será posible remontar la creación sensible, yendo de las bellezas más inmediatas a las mediatas, de manera que se llegue a esa Forma infabricata y hermosísima que es Dios mismo. En este sentido, dirá Agustín que «la razón puede progresar, escalando de lo visible a lo invisible, de lo temporal a lo eterno. Porque no es vano e inútil ejercicio el de la contemplación del cielo, del orden de las estrellas $)^{4} y$ de todo lo creado que se ofrece en su belleza a los ojos del que contempla. El camino emprendido entonces será, justamente, el de un ascenso contemplativo ontológico, que irá de lo inanimado hasta Dios, teniendo presente que «la contemplación de estas cosas no ha de ser pábulo de una vana y volandera curiosidad, sino escala para subir a lo inmortal y siempre duradero» $\%^{5}$. Atiéndase a esto con más detalle.

En primer lugar puede verse el papel que la belleza de lo natural encuentra en el universo agustiniano; todo ente se revela como algo bueno, bello y verdadero, como una ocasión de acceso a lo divino que sólo es posible para el ojo atento a la contemplación. Este es el lugar y sentido principal de la creación, ser una especie de libro, un tipo de revelación que, al modo de las Escrituras, conduce al reconocimiento del Creador:

2 Sería bueno desarrollar en este mismo sentido, la raiz de los obstáculos para una adecuada percepción de lo bello, como así también su solución a partir de las virtudes teologales, pero tal empresa excedería los límites permitidos a la extensión de este trabajo.

3 Platón, Symposium, 211c, trad. de Martínez Hernández, M., Lledó Íñigo, E., García Gual, G., Gredos, Madrid, 2000: «he aquí, pues, el recto método de abordar las cuestiones eróticas o de ser conducido por otro: empezar por las cosas bellas de este mundo teniendo como fin esa belleza en cuestión (...)m.

4 Agustin de Hipona, San, De Vera Religione, edición bilingüe, trad. de Capánaga, Victorino, BAC, Madrid, 1975, 29,52 .

3 Idem. 
Por consiguiente, la Creación como la Escritura, asume la naturaleza de un libro, testificando a su autor: como la Escritura y la Encarnación de la Palabra de Dios, ella contiene y engendra simbolos, alegorias, y de hecho, sacramentos, los que permiten que se vea más claramente el sentido invisible y espiritual -de su Creador-, en y a través de lo visible ${ }^{6}$.

Agustín resalta el carácter simbólico de la Creación y puede hacerlo porque está seguro de la bondad y belleza de todo ente; porque cree que todo proviene directamente de las manos de Dios sin la mediación de un Demiurgo, actividad que podría significar el inicio del mal al implicar materia, la raíz maniquea del mal.

En segundo lugar, conviene indicar la ubicación que el Hiponense asigna a esta belleza sensible dentro del concierto de la Creación. Se debe comprender que «el mundo de las hermosuras materiales fluye con la arrebatada corriente del tiempo. Pues él ocupa la grada ínfima»' ${ }^{7}$. Una vez que se ha defendido la belleza material, es preciso darle el lugar que le corresponde; y éste es el primero y más elemental en la totalidad del universo, se trata del primer extremo en la cadena de entes bellos, el menor representante de la Belleza. Y es esta lejanía que tiene con ese Absoluto lo que constituye a la vez su grandeza y su pequeñez. Es su grandeza, porque se trata del escalón más asequible a todo ser humano, aquél que lo encuentra donde éste habitualmente vive, es decir en el nivel de la sensibilidad, permitiéndole de esta manera empezar el ascenso. Sin embargo, constituye también su pequeñez, porque la belleza material es el extremo inferior, el primero y no definitivo de los estadios por recorrer. Esto significa que no debe ser tomada como el todo, ya que sacada de su ámbito propio por el ojo no purgado incapacitaría al hombre para llegar al Dios-Belleza: «Pues la variedad poliforme de las hermosuras temporales, filtrándose por los sentidos del cuerpo, arrancó al hombre caído de la unidad de Dios, con un tumulto de afectos efimeros: de aquí se ha originado una abundancia trabajosa y, por decirlo así, una copiosa penuria, mientras corre en pos de esto y lo otro y todo se le escabulle de las manos» ${ }^{8}$. Si ahora la belleza sensible ha dejado de ser un camino de acceso al Creador, y ha devenido fuente de penurias, ¿qué es lo que ha operado esta transformación? ¿Cuál es la razón de esto en última instancia? Agustín lo dice sutilmente, pero podría formulárselo de la siguiente manera: la cuestión no es tanto la Creación misma, cuanto el modo de ver esa Creación. El Hiponense dice: el hombre ha caído, el hombre está afectado por el pecado original, el ser humano tiene una enorme dificultad para ver correctamente lo que es, debido a la falta primigenia, y así se siente impelido al error grave de tomar la creatura por el Creador. Éste es el origen de que lo bello sensible se haga un motivo de dolor.

Por último, y en tercer lugar, es conveniente reflexionar sobre el sentido que tiene este ascenso en el De Vera Religione. Se debe notar que este camino, cuyo fin es la contemplación de la Belleza Absoluta, presenta instancias intermedias de gran importancia. Por esto

HARrison, Carol, Beauty and revelation in the thought of Saint Augustine, Clarendon Press, Oxford, 1992, p. 120.

Agustin de Hipona, San, De Vera Religione, 21, 41 : «...nam ideo extrema est».

Idem. 
es que Agustín, luego de recorrer el mundo sensible tanto en su faz inanimada como en la animada, llega a una primera altura donde pone de manifiesto que el alma racional es la cima de la creación sensible, y que su actividad propia es la de juzgar de las otras cosas:

\section{(...) Mas el juzgar de los cuerpos no es propio del que solamente tiene senti- dos, sino también del que usa de razón; nosotros las aventajamos (refirién- dose a los seres animados) en lo que a ellas les falta. Pero es una verdad facilisima de comprender cuán superior es el que juzga a la cosa juzgada. (...) Por lo cual resulta evidente que, así como la vida sensitiva es superior al cuerpo, la racional supera a las dos ${ }^{9}$.}

Si el hombre es la cima de la creación sensible por ser racional, por su capacidad de juzgar todo, entonces parecería ser la misma razón el criterio de todo juicio, de manera tal que algo se diría bello, si así lo viera la inteligencia humana. Sin embargo, Agustín nota que la mente no puede ser ese criterio último, pues es «patente su mutabilidad» ${ }^{10}$, de allí que será necesario seguir remontando el ascenso y llegar a una instancia donde sea posible encontrar algo firme que sustente a todo juicio y lo habilite para decir si algo es bello o no.

\section{La percepción intelectual de lo bello}

En diversas ocasiones, a lo largo del De Vera Religione, el Hiponense apela a la descripción de la fachada de una casa para poner de manifiesto algunas de las estructuras inteligibles de lo bello. En este sentido dice que «(...) ciertamente hay que indagar por qué al colocar contiguas dos ventanas, no una sobre la otra, sino una al lado de la otra, nos ofende que una de ellas sea mayor o menor, habiendo podido ser iguales; y si la una está sobre la otra, y ambas son desiguales en la mitad, no nos ofende tanto aquella desproporción»" ${ }^{11}$. Las ventanas de la casa son motivo de una posterior reflexión sobre la armonía, la unidad y la simetría, que concluye advirtiendo que «una especie de instinto natural nos dirige a estas percepciones estéticas» ${ }^{12}$.

El significado de este texto es claro: la naturaleza humana espontáneamente tiende a alabar o aprobar aquello que percibe como armónico, aquello cuya percepción agrada ${ }^{13}$. Estas pocas líneas son decisivas para comprender el porqué de la experiencia metafísica de la belleza y su unidad. El Hiponense reconoce con la tradición que lo bello es armonía,

\footnotetext{
$9 \quad$ Ibidem, 29, 53.

$10 \quad$ Ibidem, 30, 54.

11 Idem.

12 Idem. Permítaseme hacer una indicación rápida sobre el texto, el cual dice, en la versión latina, «ita enim primo quasi natura ipsa consulitur quid probet» (así, en primer lugar, ella misma se decide a alabar como por naturaleza). La utilización de la palabra instinto en la traducción parece en este caso inapropiada pues la misma hace referencia principalmente a la dimensión irracional del hombre, cuando en realidad el texto está refiriéndose con claridad al momento del infelecto. Sin embargo, se puede conservar el sentido metafórico de este término, de manera que se lo entienda como una actividad espontánea de la inteligencia.

13

Ibidem, 30, 55 .
} 
proporción, igualdad y unidad, y otras tantas estructuras inteligibles en las que la belleza inasible se muestra. Mas esa realidad metafisica de lo bello encuentra en el mundo creado a un ser que es capaz de reconocerla y gozarla. En este punto surgen dos preguntas: ¿en virtud de qué el hombre es la única creạtura capaz de percibir lo bello?, o bien, ¿qué es este instinto natural que lleva a la aprobación de algo como bello?; y además ¿es esto lo que hace posible tal percepción, lo que brinda también unidad a la experiencia de lo bello?

\section{1. Las leyes eternas}

La preferencia agustiniana por la arquitectura, encuentra una confirmación más cuando el Hiponense decide, justamente, ahondar en la naturaleza de la percepción de lo bello. El autor, buscando desentrañar la estructura interna de la belleza y de su captación, elabora un diálogo ficticio con un arquitecto, el cual concluye de la siguiente manera: « ¿Y por qué son bellas (las cosas)? Y si lo veo titubeando, añadiré: ¿Será tal vez porque son partes semejantes entre sí y se ènlazan y reducen a unidad y conveniencia? ${ }^{14}$. Esta pregunta retórica de Agustín busca indicar aquello que es esencial a lo bello: la unidad que nace de la armonía. Sin embargo, aquí el Hiponense quiere avanzar en el plano de la captación de lo bello, y es por esto que vuelve a interrogar al arquitecto de la siguiente manera:

¿Cómo conoces aquella unidad, según cuya norma juzgas de los cuerpos, pues, careciendo de su idea, no podrías sentenciar que no la consiguen perfectamente; y si ella fuera objeto de una percepción empírica, no dirias con verdad que, aunque ostentan el sello de un vestigio, sin embargo, distan mucho del arquetipo, pues los sentidos orgánicos sólo alcanzan lo corporal ${ }^{15}$

Hay aquí varios elementos dignos de mención. Como puede verse, lo que Agustín quiere que se comprenda es que la unidad no es algo pasible de ser visto con los ojos del cuerpo sino que «la vemos con la mente» ${ }^{16}$. Sin embargo, si esto es así, ello no ocurre en virtud de la mente misma, sino por intervención de otro principio. En efecto, es sabido que la gnoseología agustiniana reclama, en el conocimiento de la verdad, la presencia de un fundamento que posibilite su descubrimiento. La razón es que lo verdadero posee una serie de características: ser inmutable, eterno y necesario, las cuales no pueden ser halladas ni en las cosas, ni en los hombres mismos, donde claramente reina la mutabilidad, la perentoriedad y la contingencia. Si se afirmara en una conversación que el hombre es racional, la verdad allí contenida, no podría tomar su carácter de tal ni de la realidad cambiante ni de la mente humana débil y mutable, sino que sería preciso otro principio capaz de otorgar a tal juicio su carácter de verdadero. Aquí es donde se hace necesario el remontarse hasta una ley primera que, interviniendo en todo juicio, sea el fundamento de su verdad; y esto

\footnotetext{
Ibidem, 32, 60 .

Idem.

Idem.
} 
es lo que ha dado origen a aquello que los estudiosos de Agustín denominan la teoría de la Iluminación. Es en este contexto, en el que deberá entenderse la cita traída más arriba.

Pero pártase, por ahora, del primer nivel del conocimiento, es decir el de la sensibilidad. Agustín afirma que los sentidos alcanzan lo corporal. Se trata del primer peldaño del conocimiento, fuente de la experiencia empírica, que se verifica de un modo particular. En efecto, si bien Agustín admite con Aristóteles la necesidad de la sensación para formar conocimientos ciertos, para el Hiponense la sensación «es una acción que el alma ejerce $\rangle^{17}$, y no una pasión, un padecer la actividad de las cosas sobre los sentidos. Para el Doctor de Hipona, el alma es de una trascendencia absoluta sobre el cuerpo, lo que hace que «no pueda admitir que lo sensible sea recibido del objeto dentro del alma; la sensación y la imagen son así inmediatamente los productos directos del pensamienton ${ }^{18}$. El alma misma produce la sensación aunque ésta sería imposible sin las cosas creadas, ya que no hay conocimiento alguno sin cosas. Pero además hay que destacar que este conocimiento sensible responde al carácter creado de las cosas. Si es posible la sensación, es porque las cosas tienen una estructura numérica dada por Dios en la creación. Estos son los vestigios de los que habla Agustín, huellas lejanas del Creador en su Obra. Esa estructura fundacional de los seres tiene en la creación un lector válido, el hombre, quien posee -también por el acto Creador- esas mismas leyes, pero no ya de un modo entitativo sino gnoseológico. Por ello es que el ser intelectual puede, con ocasión de la actividad de las cosas sobre los sentidos, conocerlas por consonantia, pues en las cosas que actúan sobre la sensibilidad están los mismos números que la sensibilidad posee como participados de la inteligencia, de manera que si bien las cosas no producen la sensación, no obstante disponen la misma al tener aquello que ya se encontraba desde antes en el alma: «el pensamiento agustiniano puede descifrar directamente, dentro de los números de las modificaciones padecidas por su cuerpo, los números de los cuerpos exteriores que las producen» ${ }^{19}$.

De esta manera, la sensación no sólo es posible por las cosas y por el carácter activo del alma que la produce, sino principalmente por el hecho del Acto Creador, quien pone un fondo común y necesario que da números, tanto a una como a las otras.

Si ahora se piensa lo dicho en relación al diálogo con el arquitecto, se apreciará que la unidad percibida en las cosas corresponde fundamentalmente a una actividad del intelecto. En efecto, se decía allí que la referida unidad es vista con la mente; sin embargo, tal afirmación demanda una explicación que manifieste cómo es posible tal actividad.

Agustín tiene una fuerte experiencia de la contingencia de las cosas, la que -en confrontación con la necesidad $\mathrm{e}$ inmutabilidad de la verdad- le hace apelar a un fundamento seguro que justifique la presencia de esas propiedades en la verdad conocida por el hombre y supere la mutabilidad propia de las cosas y del hombre mismo. Esto reclama que Dios presida al pensamiento humano como preside a su creación. En efecto, en la creación están las cosas creadas por Dios, que son en virtud de ciertas realidades inteligibles o ideas divinas, «arquetipos de toda especie o de todo individuo creado por Dios, (pues) todo ser

\footnotetext{
17 Gilson, Étienne, Introduction a l'etude de Saint Augustin, Libraire Philosophique J. Vrin, Paris, 1982, p. 113.

18 Idem.

$19 \quad$ Ibidem, p. 116.
} 
es creado a partir de un cierto modelo $\rangle^{20}$. Ahora bien, esas ideas presiden toda la creación, las cosas y la mente humana, pues «el intelecto humano es inmediatamente sumiso dentro de sus operaciones a las ideas de Dios» ${ }^{21}$. En efecto, es patente a los ojos de Agustín que en el hombre se encuentran «una serie de ideas las cuales son enteramente independientes de todo origen empírico: el número, el bien, la verdad, la belleza, la igualdad, la similitud, la sabiduría $>^{22}$. De esta manera, la inteligencia humana se mueve según estas ideas divinas, que tienen - por ser en Dios- las mismas propiedades que Él, es decir, inmutabilidad, eternidad y necesidad; y pueden, a su vez, comunicar a los juicios humanos sus mismas virtudes. Esto es lo que se ha dado en llamar iluminación.

- En el texto se aprecia que si es posible decir que algo cumple o no con esa norma de belleza que es la unidad, esto es porque la mente, aquella que propiamente ve la unidad, posee una ley o arquetipo de la misma, que actúa cada vez que se juzga si algo es uno o no; dicho de otro modo, si el hombre juzga que algo es uno o no, es porque lo hace a la luz de esa regla, la cual tiene como función no dar un contenido a los juicios, sino solamente regularlos $^{23}$. Estas ideas, entonces, iluminan y son condición de posibilidad de todo juicio, ya que dan a los mismos su carácter apodíctico.

Esto no quita importancia ni a la experiencia sensible, ni a las cosas mismas en su capacidad de ser conocidas; por el contrario establece una fuerte estructura jerárquica en el universo, donde se subraya su principal unidad, la cual está fuertemente cimentada en Dios Creador. El acto creador establece y enlaza esa jerarquía de seres, a la vez que hace posible el conocimiento de éstos por el hombre. Él es quien preside todo desde la Unidad.

Aplicado a la belleza todo lo dicho hasta aquí es aún más claro. Si se ve un ente bello, este esplende en su belleza por la intensa presencia del número, que conlleva la forma y de la que se siguen la armonía, la proporción, la unidad, etc. Ante esto, sólo el ser intelectual. puede quedar asombrado; sólo el hombre puede percibir, en virtud de la mente, la belleza alli presente. Tal actividad implica a todo el hombre, es decir, su dimensión sensible e intelectual. Con todo, no basta ser intelectual para poder ver lo bello, sino que es preciso que se posea una ley de belleza, es decir una idea de lo bello, que actúe en cada juicio y permita que este alcance la apodicticidad propia de lo Bello Absoluto:

\begin{abstract}
Que yo tenga la idea de un arco visto en Cartago, es totalmente natural, ya que yo la he visto; pero que la curva de este arco me agrade y la juzgue bella, esto es algo que no se explica con la sola idea de la experiencia. Para juzgar de lo que las cosas deban ser, debe ser necesario que nuestro pensamiento racional esté sumiso a la acción de aquellas ideas y esto es, de nuevo aqui, lo que nosotros denominamos iluminación ${ }^{24}$.
\end{abstract}

\footnotetext{
$20 \quad$ Ibidem, p. 109.

Idem.

22 Ibidem, p. 121.

23 Cfr. ibidem., p. 123: se puede «admitir que la iluminación da los conceptos concebidos como fundamentos de ciertos juicios, sin conceder a esta iluminación un rol más que regulador y formal».

24 Gilson, Étienne, Introduction..., op. cit., p. 120.
} 
La iluminación no hará más que regular y posibilitar todo conocimiento intelectual de lo bello como tal. Pero más aún, pues su poder regulativo se extenderá a toda consonantia que aparezca en el proceso cognoscitivo: desde aquella que se encontraba en la sensibilidad, hasta esta intelectual, donde los números presentes en las cosas disparan, a causa del sonar en el mismo tono, la actividad iudicativa que supone la posesión de esos mismos números o leyes pero sólo en un modo regulativo ${ }^{25}$. En definitiva, esta dependencia muestra el profundo estado creatural del hombre, quien necesita de la asistencia divina hasta en esa actividad que es la determinación de la verdad, belleza, unidad, etc., de algo.

Queda claro el papel de la iluminación y de la necesidad de las ideas eternas para regular y dar apodicticidad a los juicios.

El examen del texto ha dado razón de la percepción sensible e intelectual de lo bello; pero ahora invita a dar un tercer paso: si se atiende a su comienzo, podrá verse que la intención de Agustín es la de referirse al conocimiento de esa ley, de esa idea, de esa norma de unidad más que a otra cosa. En otras palabras, el fin principal de la pregunta formulada al arquitecto no es sólo por cómo juzgo que algo es bello, sino que apunta a la posibilidad de conocer el último fundamento de esos juicios, es decir que se pregunta si es posible conocer a la unidad misma y, por consiguiente, a la belleza pura.

Lo primero que el Hiponense indica de estas leyes, de estas ideas divinas, es su existencia y su carácter absoluto. Y así dice que,

\section{(...) conociendo el alma que discurre de la hermosura y movimiento de los cuerpos con normas superiores a si misma, debe reconocer al mismo tiempo que ella aventaja según su ser a las cosas, sujetas a su juicio; pero, a su vez, es inferior en excelencia a aquella naturaleza que regula sus juicios, y a la cual no puede juzgar de algún modo ${ }^{26}$.}

El hombre es superior a las cosas en su ser mismo y por ello puede juzgarlas; pero a la vez, este ser humano no es el fundamento último de tales juicios sino que por encima suyo existen estos absolutos, acerca de los cuales no es posible hacer juicio alguno ${ }^{27}$. Atiéndase brevemente a este punto.

Debe notarse aquí una importante diferencia entre el conocimiento de las cosas y el de estas leyes. Respecto de las primeras, Agustín indica que se puede juzgar, es decir, determinar mediante la iluminación, la verdad, belleza, unidad, etc., de algo. Sin embargo, al

25 Hay que insistir junto a Gilson en el carácter regulativo de lạs ideas divinas en la iluminación, debido a que sería sencillo caer en un innatismo de ideas. Sin embargo, el pensamiento agustiniano rechazará tal posibilidad. De allí que no se tratará de una presencia de estas leyes en la inteligencia a modo de un contenido cognoscible, sino solamente de la existencia en ella de estructuras inteligibles ordenadas a la regulación de los juicios; y no de todos indistintamente sino únicamente de aquellos que miran al deber ser de algo.

26 Agustín de Hipona, San, De Vera Religione, $31,57$.

27 Sobre esto, también se puede ver: ibidem., 43, 81: «la misma regla del orden vive en la verdad eterna, sin ser grande por su masa ni alterable por su prolongación; antes bien es trascendente y superior a todos los lugares, inmóvil con la eternidad sobre los tiempos; mas sin ella ninguna grandeza cuantitativa pudiera reducirse a unidad, y ninguna prolongación temporal medirse sin error, ni haber algo que tenga los elementos constitutivos del cuerpo o los del movimiento». Nada sería sin estas reglas, idénticas con Dios, como dirá en el comienzo de 31,57 , ya que las mismas posibilitan tanto la existencia de las cosas como su conocimiento intelectual por parte del hombre. 
referirse a las leyes que posibilitan esos mismos juicios, el Hiponense refiere que ya no es posible juzgar sino sólo constatar su existencia. Dicho de otra manera: estas leyes sólo pueden ser vistas, o mejor aún contempladas en el asombro de su existencia, mas no es posible dar de ellas una razón de ser, un fundamento previo, una causa, sino que justamente son la Causa y el Fundamento de todo lo demás. De allí que Agustín distinga entre cognoscere y iudicare al decir que «para conocer basta ver si una cosa es o no; pero para juzgarla añadimos más, indicando que puede ser de otra manera, como cuando decimos: asi debe ser, o así debió ser, o así deberá sern ${ }^{28}$. Es claro que aquí el conocimiento recae sobre la existencia de algo sin pretender ir más allá; por el contrario el juicio no se detiene allí sino que avanza sobre lo contingente con la intención de develar al deber ser del mismo. De esta manera es que se puede juzgar de todo lo creado, ya que la luz de esas leyes eternas permite ver en el particular su relación con el arquetipo, de manera que aparezca el grado de belleza o unidad en comparación con su deber ser. Sin embargo, respecto de los arquetipos mismos, es decir, de esas leyes de belleza, la posibilidad de juicio desaparece, quedando sólo el simple conocer, es decir, el puro ver su existencia sin ninguna clase de discurso.

Lo mismo se puede encontrar más adelante, en el De Vera Religione, cuando el Hiponense ofrezca un sintético compendio de todo lo dicho hasta ahora respecto de las cosas, los juicios y el cognoscere:
(...) invitados por las cosas, sometidas a nuestro juicio, a examinar la natu- raleza de nuestra potencia judiciaria, y subiendo de las obras artísticas a la ley de las artes (legem artium), contemplaremos (contuebimur) con la mente aquella hermosura en cuyo parangón resultan deformes las criaturas que son bellas por su benignidad ${ }^{29}$.

Una vez más aparece indicado el orden jerárquico: cosas, juicio y conocimiento de las leyes reguladoras del pensar. A su vez, se ve también cómo la instancia última posible al hombre, a la que el Hiponense quiso llevar al arquitecto, es esta ley de las artes, la cual, por un lado, regula el juicio sobre la belleza de todo lo creado, pero, por otro, es gozada en la contemplación. Esto lleva a considerar con más detenimiento la naturaleza de esa actividad máxima por la que se contempla esta ley de belleza.

Véanse los términos que Agustín ha reservado para hablar de esta actividad por la que la mente ve las leyes eternas, donde aparece tanto la utilización del verbo contueor, como la del verbo cognoscere. Lo significativo es que en ambos casos se trata de un ver (videre) de particulares características, que lleva a lo que se conoce tradicionalmente como intuición.

Si bien la lectura del De Vera Religione no indica cómo se da la actividad intuitiva en el hombre, es un hecho que Agustín postula su existencia. La referencia textual así lo muestra. Sin embargo aún se puede avanzar un poco más.

En primer lugar, hay que decir de la intuición que ésta encuentra su analogado más patente en el sentido de la vista. En efecto, «la palabra intuición -intueri- nos viene en

$28 \quad$ Ibidem, 31, 58 .

29 Ibidem, 52, 101. 
préstamo del sentido de la vista» ${ }^{30}$, ya que éste alcanza lo conocido en el mismo acto de conocer, o mejor aun, alcanza su acto propio en un solo paso: ve y ve. Compárese este conocimiento con la actividad racional. En esta última, el acto de conocimiento supone un discurso extenso, donde se procede de una afirmación a otra, de manera que la verdad de algo se ve sólo después de la mediación del discurso. Aquí justamente, ya no se ve en el mismo acto propio de la inteligencia, sino que esa visión aparece al final del razonamiento: la visión está mediada.

Ahora bien, Agustín, sin desarrollar ampliamente este ver propio del cognoscere, parece darle una clara connotación intuitiva: más allá de que se pueda razonar para alcanzar estas leyes divinas, las mismas se ven o no; es decir que su conocimiento total ${ }^{31}$ se alcanza en el mismo acto en el que se las ve, y nada más hay que hacer con ellas que verlas. De allí que el Hiponense hable de que en el ver se constata la existencia de estas leyes, pues el hecho de que las cosas sean, es el primero y más intuitivo dato que la inteligencia humana alcanza; luego vendrá el discurso que busque la definición, es decir, que revele el qué es, pero ese acto primigenio e intuitivo, ya habrá pasado.

En el mismo sentido se puede atender a las Confessiones, donde una vez más aparece este cognoscere bajo un nuevo nombre -relacionado a ese ver intuitivo- a la vez que se habla también del iudicare:

(...) Porque buscando yo de dónde aprobaba la hermosura de los cuerpos -ya celestes, ya terrestres- qué era lo que había en mi para juzgar (iudicanti) rápida y cabalmente (presto esset integre) de las cosas mudables cuando decia: "Esto debe ser así, aquello no debe ser asi»; buscando, digo, de dónde juzgaba yo cuando así juzgaba, hallé que estaba la inconmutable y verdadera eternidad de la verdad sobre mi mente mudable.

Y fui subiendo gradualmente de los cuerpos al alma, que siente por el cuerpo; $y$ de aqui al sentido íntimo, al que comunican o anuncian los sentidos del cuerpo las cosas exteriores, y hasta el cual pueden llegar las bestias. De aqui pasé nuevamente a la potencia raciocinante (ratiocinantem), a la que pertenece juzgar de los datos de los sentidos corporales, la cual, a su vez, juzgándose a sí misma mudable, se remontó a la misma inteligencia (intelligentiam), y apartó el pensamiento de la costumbre, y se sustrajo a la multitud de fantasmas contradictorios para ver de qué luz estaba inundada, cuando sin ninguna duda clamaba que lo inconmutable debia ser preferido a lo $\mathrm{mu}$ dable; y de dónde conocia yo lo inconmutable, ya que si no lo conociera de algún modo, de ninguno lo antepondría a lo mudable con tanta certeza. $Y$, finalmente, llegué a «lo que es» en un golpe de vista trepidante (quod est in ictu trepidantis aspectus) ${ }^{32}$.

CAPÁNAGA, Victorino, «La doctrina Agustiniana sobre la intuición», en Augustinus XXIII, 89/92, 1978, p. 73. Entiéndase aqui por conocimiento total, no el que agota la esencia de estas leyes sino el que percibe intensamente que las mismas son, y que son de algrín modo; esto segundo puede aparecer con mayor o menor precisión, sin embargo, el hecho de que existan, es de una evidencia total. 
En primer lugar, Agustín vuelve a mencionar la teoría de la iluminación: no se puede juzgar acerca del deber ser de algo, si no se posee una regla de verdad, la cual excede infinitamente a la razón humana.

Pero el texto agrega algo de gran importancia: la distinción que Agustín establece entre ratio e intelligentia. La primera, siendo uno de los tipos de actividades propias del alma intelectual tiene por objeto al juicio que recae sobre los datos sensibles o sobre el pensar mismo, de modo que su actividad, si bien encuentra su última justificación en la iluminación, está abocada a lo múltiple y discursivo ${ }^{33}$. Por otro lado, aparece una segunda operación del alma intelectiva, que es llamada, en el texto, intelligentia. Aquí ya no se trata de una actividad que verse sobre los datos sensibles, sino que Agustín, tal como lo hiciera en el $D e$ Vera Religione con el cognoscere, parece designar con este término al acto propio del alma intelectual, por el cual puede conocerse a sí misma y a las leyes reguladoras del pensar, pero de modo intuitivo. La intelligentia se presenta como una actividad del alma mucho más estable e inmutable que la ratio; más aún, es la que puede ver de algún modo que lo mudable depende de lo inmutable y, además, es la actividad que propiamente ve o puede ver esas leyes eternas que regulan nuestro conocimiento verdadero. Aquí el Hiponense se hace más claro todavía: ese ver es ictus aspectus trepidans, es decir, un ver, una mirada que no es sensible sino claramente intelectual; a su vez, ese ver aparece calificado por el ictus, de manera que se trata de un ver de golpe, pero que a la vez es un ver conmovido; y por último, se trata de un ver de golpe y conmovidamente trepidante, es decir, intenso, rápido.

Agréguese que la existencia de esta actividad intuitiva en el alma queda reforzada por los mismos términos que Agustín utiliza para referirla ${ }^{34}$ : «son frecuentes los vocablos como cernere, contemplari, splendor, relativos a la inmediatez de la captación del objeto bello o bien a su claridad patente a los sentidos. (...) En repetidos pasajes del Hiponense aflora este intuicionismo, que dice una relación muy íntima con la manifestación del orden por parte del objeto bello y con el goce que inmediatamente brota en el contemplador ${ }^{35}$.

A partir de esto, es claro entonces, el carácter intuitivo que esta operación intelectual presenta. En tal sentido, Gilson sostiene que esta clase de conocimiento, el que versa sobre las ideas eternas, lejos de formar parte del conocimiento más común del hombre, es decir, de aquel que se ocupa de las cosas creadas juzgadas a la luz de dichas ideas, constituye un tipo de conocimiento místico: «cada vez que Agustín habla de conocimiento, o de ver, las razones eternas y la luz divina, es sobre el conocimiento místico de lo que él trata» ${ }^{36}$. Que esto sea así, no quita justamente, sino que demanda, lo intuitivo de dicho conocimiento, a la vez que se coloca -se puede agregar-como el analogado principal del conocimiento hu-

33 Sobre esto, Agustín ya había dado una descripción de la razón en el De Ordine cuando indicaba que la «Razón es el movimiento de la mente capaz de discernir y enlazar lo que conoce»s. Cfr. Agustín DE Hipona, San, De Ordine, II, 11,30 .

34 Se puede indicar, como ejemplo, junto a las citas ya referidas, la siguiente: «(...) Y subiendo de las obras artísticas a la ley de las artes, contemplaremos (contuebimur) aquella hermosura...» Agustin DE HiponA, San, De Vera Religione, 52, 101 .

35 Rey Altuna, Luis, «La actitud estimativa de lo bello en San Agustín», en Augustinus 10-11, 1958, p. 356.

36 Gilson, Étienne, Introduction..., op. cit., p. 126. 
mano. En otros términos: si bien el modo habitual de conocer es el de la ratio, donde interviene la iluminación y donde no se conocen las leyes eternas que la regulan sino que sólo se enjuicia lo real, tal conocimiento es un reflejo de aquella actividad que pone al hombre en proximidad con las ideas eternas; no se trata entonces de que haya una discontinuidad entre juicio y cognoscere o intelligentia, de manera que una y otra sean completamente distintas, sino que lo que reina entre ellas es una diferencia de grado: una es más intuitiva que la otra, es decir, el cognoscere es propiamente intuitivo, y el juicio participa a su modo y en grado inferior de aquel tipo de conocimiento. Hay que recordar que ambas actividades, si bien se distinguen por su objeto, con todo, son actividades de la misma potencia, es decir de la inteligencia cuyo sentido propio es el de ver.

En esta interpretación propuesta se gana unidad en la dinámica de la inteligencia, permitiéndose la comprensión más profunda del texto citado; allí decía el Hiponense que juzgamos rápida y cabalmente al aprobar la hermosura de los cuerpos. La intuición está de modo principal en la intelligentia o cognoscere; sin embargo, al juzgar acerca del deber ser de las cosas, una vez más, se ve su proximidad o alejamiento de ese deber ser. En otras palabras, si bien hay una mediación que aleja de la intuición y aproxima más al discurso, no.obstante sigue tratándose de un ver, que se da rápida y cabalmente, y que participa de alguna manera del conocer intuitivo.

Se concluye entonces que el hombre es capaz de conocer lo bello, no sólo en el momento sensible sino propiamente en el momento intelectual que es, junto con la iluminación, el fundamento de dicha percepción. Ese conocimiento de lo bello, el cual puede darse tanto al nivel del juicio como al nivel de la intelligentia, siempre goza de un cierto carácter intuitivo: más pleno en la segunda y menos en el primero.

Pero el Doctor de Hipona no se queda satisfecho todavía con esta respuesta; necesita encontrar ese principio último que sea la base de toda percepción de lo bello y que se identifique con las leyes eternas mismas; necesita saber, en última instancia, qué es lo que hay en el hombre que le permite percibir esa ley de unidad y belleza. Tal cosa, dirá Agustín, es el hecho de la semejanza: «el hombre se dice muy bien que fue hecho a imagen y semejanza de Dios, pues de otro modo no podría percibir con su mente la inmudable verdad» ${ }^{37}$. Todo lo explicado hasta aquí encuentra su justificación más radical en el hecho de que el hombre es semejante a Dios. No se trata sólo del hecho de la creación sensible, donde Dios pone en la existencia cosas bellas; no se trata sólo de la iluminación y la capacidad iudicativa o intelectiva del hombre, por la cual se perciben las cosas bellas. Todo lo que es, guarda una huella, un vestigio, una semejanza, que en el caso del hombre es imago, y le da la posibilidad de conocer en ese nivel intelectual, que es una imagen lejana del Verbo de Dios, Verdadera Imagen del Padre. De esta manera la capacidad perceptiva intelectual del hombre, una vez más, es referida al Creador, y en concreto, al Verbo.

Se ve así la importancia que la semejanza tiene en la percepción de lo bello y verdadero. Pero además, esto muestra que esa semejanza se da tanto entre el Verbo y el intelecto, como entre el Verbo y el resto de lo creado, pues, según se ha indicado, es posible hallar

37 Agustín de Hipona, San, De Vera Religione, 44, 82. 
vestigios del Creador en todo lo que es. Esto es lo que da a la experiencia de lo bello y de lo verdadero, una intensa unidad metafisica.

\section{La unidad de la experiencia metafísica de lo bello}

Se ha advertido que, en última instancia, lo que permite al hombre ver la verdad de las cosas y a la verdad misma, en cuanto principio regulador del intelecto, es la semejanza con el Verbo. Sin embargo, también ha quedado claro que el obrar creador no deja de plasmar en sus criaturas lo que Agustín llama vestigios, es decir, los números o formas eternas presentes desde siempre en la mente divina. Más aún, se ha indicado oportunamente, que esa numerosidad de las cosas y del hombre posibilita una consonantia, que es el primer disparador del conocimiento sensible, ya que el alma al producir la sensación actualiza los números participados por el intelecto a la sensibilidad. De esta manera, puede apreciarse que toda la realidad, desde el momento en que el hombre entra en relación con ella, cobra una intensa unidad ya que las cosas alcanzan un nivel que por sí mismas no podrían. No se trata de que las cosas sólo sean, sino que al consonar con el hombre éstas encuentran una unidad superior; más aun, el hombre mismo se inserta en esa unidad que lo precede pues al entrar todo en consonancia, al ocupar cada uno su lugar en el universo, éste se unifica y el Principio último de todo se hace más y más luminoso.

Lo que se quiere señalar es que la percepción intelectual de la verdad, la belleza, o la unidad, sea en el caso del juicio, sea -de modo más propio-, en el del cognoscere, conlleva una profunda experiencia metafisica unitaria del Verbo Divino ${ }^{38}$ : es el Verbo, en última instancia, el responsable de esa unidad que se da en la consonantia, pues es el que está presente en las cosas a modo de vestigios, y está presente también en el hombre a modo de imagen. Así, por una parte, posibilita toda experiencia de lo bello al dar los números divinos a todo lo que es, pero por otra es también el que da unidad a dicha experiencia, ya que está en el origen y término de la misma ${ }^{39}$.

Agustín no cesa de anunciar esto: todo vestigio debe ser una ocasión de comprender, en virtud de la semejanza, que uno y otra responden al Verbo que los dio gratuitamente, pues si el hombre no comprende tal cosa, sólo le queda el camino de la dispersión en las criaturas, donde reinará la multiplicidad propia del sinsentido:

38 Con esto no se quiere decir que en cada conocimiento verdadero donde se reconozca también la belleza de una cosa se esté viendo al Verbo de Dios; sólo se quiere decir que -sin verlo- el hombre de mirada profunda experimenta su presencia y necesidad, como Absoluto. Nada se daría sin Él, y toda la consonancia y armonia del universo, en la que intervienen las cosas y el hombre mismo, encuentran en Él su primer y último responsable.

39 En este sentido, el De Trinitate será la obra que lleve a término estas afirmaciones: «La obra De Trinitate coronará de manera espléndida estas observaciones. Todo producto del arte divino muestra una cierta unidad, una cierta figura, una cierta ordenación. Todo ser es, en cierto sentido, «uno», (...). Y todo ente está formado con cierta «figura» (...); y cada ente se mueve hacia un cierto «orden» y se establece en él; por su propio peso, los cuerpos son llevados a su sitio, y las almas por sus placeres y deseos (De Trin. VI, 10, 12). Así en toda criatura aparece una huella o trasunto de la Trinidad (ibidem, 10,11). La doctrina sapiencial de la belleza se convierte, en Agustín, en una estética de la Trinidad». De BruYne, Edgar, Historia de la Estética. II, trad. de Suárez, Armando, BAC, Madrid, 1963, p. 313. La cursiva es nuestra. 
Y si a nosotros nos embauca la hermosura material, por la unidad que ostenta, sin lograrla plenamente, entendamos, si podemos, que nuestra ilusión procede no del ser, sino del no ser de ellas. Pues todo cuerpo es verdadero cuerpo, pero falsa unidad; $y$ no obstante, ni el cuerpo mismo existiría sin ser uno de algún modo, (...) no podría serlo sin participar lo que tiene de la perfecta unidad ${ }^{40}$.

Ni las cosas serían unas sin la participación de la Unidad divina, sin ese vestigio, ni los hombres podrían juzgar que las cosas lo son si no fuera por esa semejanza. Dicho de otra manera, la unidad y la belleza todo lo envuelven, y están presentes a todo, sea por participación inconsciente (en las cosas) sea por participación consciente (en el hombre), no sólo dándole unidad en sí mismo sino, además, dándole la posibilidad de juzgar de la unidad de las cosas y de conocer la existencia de esa ley de unidad, que es la Unidad misma.

Se ve que la experiencia de lo bello en el hombre, cuando está guiada rectamente, cuando se alcanza de modo adecuado, le permite conseguir una intensa unidad de él con las cosas y con el Creador. Esto es lo natural y lo que debería ocurrir, y de donde brota el gozo propio de lo bello. Sin embargo, si esa preparación no está operada, si no se ha hecho un camino propedeútico para esa experiencia de lo bello, esto mismo puede ser motivo de un alejamiento de la unidad buscada. Como se leía en el texto, no todo hombre está así preparado, sino que la mayoría se pierde en los fantasmas de la imaginación, en los laberintos de lo inventado, en ese no ser que es fuente de ilusión, donde lo bello y la unidad que ella implica llevan justamente a la dispersión; por ello es que Agustín insistirá en la importancia de eliminarlos: «combatid sólo los hábitos de la fantasía corporal; vencedlos, y vuestra victoria será completa» ${ }^{41}$. Y ese combate-dada la condición del hombre caído- no podrá ser sino desde las virtudes teologales.

\section{Conclusión}

Para concluir este trabajo quisiera destacar ese rasgo característico del pensamiento medieval que tiene como centro la experiencia de una intensa unidad, algo que Agustín ha sabido profundizar con genio particular. Desde el Creador y la creatura, pasando por el hombre como cima de esa creación, hasta la filosofia y la teología, la especulación agustiniana se muestra, al menos en el aspecto que aqui se ha desarrollado, fuertemente unitaria. En ella no hay enfrentamientos entre sujeto y objeto, donde lo bello sería obligado a radicarse en uno u otro, sino continuas síntesis que miran a Dios como fin. Pero además ella propone un pensar que invita a una experiencia, a recorrer un camino que se inicia con la belleza y que termina con la Belleza, un ascenso que encuentra al hombre caído en el nivel donde vive habitualmente, el de la sensibilidad, y lo eleva hasta el nivel humano del intelecto, llegando al conocimiento de las leyes que lo gobiernan. Un camino posible al

\footnotetext{
Agustin de Hipona, San, De Vera Religione, 34, 63.
}

Agustín de Hipona, San, De Vera Religione, 35, 65. 
hombre por la consonantia presente a todo, pero un camino que demanda la purificación de la mirada a manos de las virtudes teologales. Este último punto, cuyo tratamiento ha sido desplazado dada la extensión permitida a este trabajo, constituye sin duda un aporte fundamental y una radical diferencia con el pensar antiguo*.

\section{Bibliografía}

Agustín de Hipona, San, Confesiones, trad. de Vega, Ángel Custodio, BAC, Madrid, 1991. rino, BAC, Madrid, 1975. , De Vera Religione, edición bilingüe, trad. de Capánaga, Victoino, BAC, Madrid, 1975 . , De Trinitate.

, De Ordine.

CAPÁNAGA, VICTORINO, «La doctrina agustiniana sobre la intuición», en Augustinus XXIII, 89/92, 1978, pp. 71-86.

De BruYne, Edgar, Historia de la Estética. II, trad. de Suárez, Armando, BAC, Madrid, 1963.

Gilson, ÉTIENNE, Introduction a l'etude de Saint Augustin, Libraire Philosophique J. Vrin, Paris, 1982.

Platón, Symposium, 211c, trad. de Martínez Hernández, M., Lledó İ̃nigo, E., García Gual, G., Gredos, Madrid, 2000.

Rey Altuna, Luis, «La actitud estimativa de lo bello en San Agustín», en Augustinus 1011, 1958, pp. 351-358.

- Artículo Recibido: 3 de septiembre de 2009. Aceptado: 13 de octubre de 2009. 